\title{
BMJ Open Effect of once-daily indacaterol maleate/mometasone furoate on exacerbation risk in adolescent and adult asthma: a double-blind randomised controlled trial
}

\author{
Richard W Beasley, ${ }^{1}$ James F Donohue, ${ }^{2}$ Rajendra Mehta, ${ }^{3}$ Harold S Nelson, ${ }^{4}$ \\ Michelle Clay, ${ }^{5}$ Allen Moton, ${ }^{6}$ Han-Joo Kim, ${ }^{6}$ Bettina M Hederer ${ }^{7}$
}

To cite: Beasley RW, Donohue JF, Mehta R, et al. Effect of once-daily indacaterol maleate/mometasone furoate on exacerbation risk in adolescent and adult asthma: a double-blind randomised controlled trial. BMJ Open 2015:5:e06131.

doi:10.1136/bmjopen-2014006131

- Prepublication history and additional material is available. To view please visit the journal (http://dx.doi.org/ 10.1136/bmjopen-2014006131)

MC, AM and H-JK have since left Novartis.

Received 16 July 2014 Revised 28 December 2014 Accepted 6 January 2015

CrossMark

For numbered affiliations see end of article.

Correspondence to Dr Richard W Beasley; Richard.Beasley@mrinz.ac.nz

\section{ABSTRACT}

Objective: To investigate the safety and efficacy of QMF149, a once-daily, fixed-dose combination of the long-acting $\beta_{2}$-agonist (LABA) indacaterol maleate and inhaled corticosteroid (ICS) mometasone furoate (MF) for the treatment of persistent asthma. The hypothesis was that QMF149 would not increase the risk of serious asthma exacerbations.

Setting: 174 research centres in nine countries. Participants: 1519 adolescents and adults with persistent asthma who were treated or qualified for treatment with combination LABA/ICS were randomised, and 1508 were included in the intentionto-treat analysis.

Intervention: Patients were randomised to QMF149 (indacaterol maleate $500 \mu \mathrm{g} / \mathrm{MF} 400 \mu \mathrm{g}$ ) or MF $(400 \mu \mathrm{g})$ once daily via Twisthaler inhalation device in a double-blind, parallel-group study for 6-21 months.

Primary and secondary outcome measures: The primary end point was time to first serious asthma exacerbation (resulting in hospitalisation, intubation or death). The key secondary end point was annual rate of exacerbations requiring systemic corticosteroids.

Results: Treatment with QMF149 resulted in no significant difference in time to first serious exacerbation compared to MF (2 $(0.3 \%)$ vs 6 events (0.8\%); difference -0.52 percentage point; $95 \% \mathrm{Cl}$ -1.25 to $0.21, p=0.160, \mathrm{HR}=0.31 ; 95 \% \mathrm{Cl} 0.06$ to 1.54, $p=0.151)$. QMF149 significantly reduced the annual rate of exacerbations requiring systemic corticosteroids (rate ratio $=0.71 ; 95 \% \mathrm{Cl} 0.55$ to 0.90 , $\mathrm{p}=0.005)$. Proportions of patients experiencing adverse events were similar across groups $(74.0 \%$ in the QMF149 group and $73.4 \%$ in the MF group). Serious adverse events occurred in $4 \%$ and $5.8 \%$ of patients in the QMF149 and MF groups, respectively.

Conclusions: No significant difference was observed in the primary outcome of time to first serious asthma exacerbation in patients treated with QMF149 compared with patients treated with MF. Long-term treatment with QMF149 once daily had a favourable safety/efficacy profile in adolescent and adult patients with persistent asthma.

\section{Strengths and limitations of this study}

- This randomised controlled trial provides comprehensive data on the efficacy and safety of QMF149, a once-daily, fixed dose combination of the inhaled corticosteroid (ICS) mometasone furoate (MF) and the long-acting $\beta_{2}$-agonist (LABA) indacaterol for the treatment of asthma.

- QMF149 had a favourable efficacy/safety profile, reducing the rate of severe exacerbations requiring systemic corticosteroids by $29 \%$, compared with MF therapy.

- Study findings may be generalised as the dose of indacaterol $500 \mu \mathrm{g} / \mathrm{MF} 400 \mu \mathrm{g}$ delivered via the Twisthaler device is expected to be clinically comparable to the dose of indacaterol $150 \mu \mathrm{g} / \mathrm{MF}$ $160 \mu \mathrm{g}$ delivered via the Breezhaler device, which will be the device used for QMF149 in phase III.

- The study was limited by the low rate of serious exacerbations, resulting in insufficient power to detect differences between treatment regimens.

- These findings are relevant to the issue of ICS/ LABA safety in asthma.

Trial registration number: ClinicalTrials.gov; NCT00941798.

\section{INTRODUCTION}

Inhaled corticosteroids (ICS) are the cornerstone of therapy in persistent asthma in adolescents and adults. However, in patients with moderate-to-severe disease, the addition of a long-acting $\beta_{2}$-agonist (LABA) may be required to achieve asthma control. ${ }^{1}{ }^{2}$ This concomitant use should be prescribed in the form of a combination LABA/ICS single inhaler product, as the use of separate inhalers is likely to result in LABA monotherapy during 
periods of ICS non-adherence. ${ }^{3}$ This is important as LABA monotherapy may be associated with an increased risk of mortality in patients with unstable asthma. ${ }^{4}$

Combination LABA/ICS therapy also has the advantage of improving compliance with ICS therapy, ${ }^{5}{ }^{6}$ which has the potential to reduce the risk of death due to the dose-dependent relationship between ICS use and asthma mortality. ${ }^{7}$ Existing twice-daily, fixed-dose combinations of LABA/ICS have demonstrated efficacy in randomised controlled trials. ${ }^{8}$ To date there is no evidence to suggest an increase in risk of life-threatening attacks or death from asthma with combination LABA/ICS therapy. ${ }^{10}{ }^{11}$ However, in view of a potential risk due to LABA monotherapy, highlighted by the SMART study, ${ }^{12}$ and by systematic reviews ${ }^{4}$ including a meta-analysis conducted by the US Food and Drug Administration (FDA),${ }^{13}$ it has been proposed that studies should be conducted that specifically assess this risk with currently available and novel LABA/ICS products. ${ }^{14}$

QMF149 is a once-daily fixed-dose combination of the LABA indacaterol maleate and the ICS mometasone furoate (MF), which have both demonstrated $24 \mathrm{~h}$ duration of action as monotherapies. ${ }^{15-18}$ QMF149 is under development for the treatment of asthma and chronic obstructive pulmonary disease. Increased dosing frequency has been found to affect medication compliance ${ }^{19}$ therefore, the convenience of once-daily QMF149 may help to improve treatment outcomes.

This phase II safety study was designed to investigate the impact of QMF149 compared with MF on serious outcomes of asthma-related death, intubation or hospitalisation ${ }^{14}$ in adolescent and adult patients with asthma. As this composite outcome variable represents safety and efficacy, it has allowed an assessment of the safety/efficacy profile of QMF149 in adolescent and adult asthma. QMF149 and MF were delivered via the Twisthaler inhalation device, which is the current marketed device for MF (Asmanex Twisthaler inhalation powder (Merck Sharp \& Dohme Corp; New Jersey, USA). However, as it has been demonstrated that the Breezhaler device, a single-dose dry powder inhaler, facilitates achievement of comparable clinical effect at lower doses of indacaterol and MF $(150 \mu \mathrm{g} / 160 \mu \mathrm{g}$ compared with $500 \mu \mathrm{g} /$ $400 \mu \mathrm{g}$ via Twisthaler device ${ }^{20-22}$ ), the future development of QMF149 will be via the Breezhaler inhalation device.

\section{METHODS}

This was a randomised, double-blind, multicentre, parallel-group study conducted between July 2009 and May 2011. Investigators are listed in the online supplementary appendix section 1 . All patients discontinued regular asthma maintenance therapy after giving informed consent and were switched to open-label MF $400 \mu \mathrm{g}$ once daily for the run-in period (21-28 days).

\section{Randomisation and masking}

Eligible patients were randomised in a $1: 1$ ratio to receive once-daily QMF149 (indacaterol maleate $500 \mu \mathrm{g} / \mathrm{MF} 400 \mu \mathrm{g})$ or MF $(400 \mu \mathrm{g})$ via Twisthaler inhalation device, in the evening. Randomisation numbers were generated using a procedure that ensured assignment was unbiased and concealed from patients and investigators: a patient randomisation list was produced by an interactive voice response system (IVRS; Oracle America Inc, Redwood City, California, USA) using a validated system that automated the random assignment of patient numbers to randomisation numbers. These randomisation numbers were linked to the different treatment groups, which in turn were linked to medication numbers. A separate medication randomisation list was produced by or under the responsibility of Novartis Drug Supply Management using a validated system that automated the random assignment of medication numbers to medication packs containing each of the study drugs. Randomisation was stratified by the presence or absence of the following demographic and baseline characteristics:

1. Patients who had an asthma-related hospitalisation within the 12 months prior to randomisation.

2. Patients who had experienced asthma worsening(s) that required either an emergency room visit with systemic corticosteroid, or two or more courses of systemic corticosteroids for asthma worsening during the 12 months prior to randomisation.

3. African American patients or patients of black African descent.

The study was completed per protocol when the first patient had been in the study for 21 months and/or the last patient for $\geq 6$ months. The study was conducted according to the World Medical Association's Declaration of Helsinki and approvals from institutional review boards and/or ethics committees were obtained for each investigator site.

\section{Patients}

This study enrolled patients aged $12-70$ years, with a documented diagnosis of persistent asthma for $\geq 6$ months; a prebronchodilator forced expiratory volume in $1 \mathrm{~s}\left(\mathrm{FEV}_{1}\right) \geq 50 \%$ of predicted normal and a post-short-acting $\beta_{2}$-agonist (SABA) increase in $\mathrm{FEV}_{1}$ of $\geq 12 \%$ (and $\geq 200 \mathrm{~mL}$ ) at the screening visit (3-4 weeks prior to randomisation) or who had documented reversibility within the previous 12 months; who were treated or qualified for treatment with a LABA/ICS combination $^{15}$ and had used an ICS for $\geq 2$ months prior to study start. No exacerbation history eligibility criteria were specified. Full inclusion and exclusion criteria are listed in the online supplementary appendix section 3 .

\section{Outcome measures}

The primary end point was time to first serious asthma exacerbation (resulting in hospitalisation, intubation or death). Details of event adjudication and data monitoring 
procedures are provided in the online supplementary appendix sections 4 and 5 , respectively.

The key secondary end point was cumulative incidence of serious asthma exacerbations. Other secondary end points included time to first asthma exacerbation and rate of exacerbations requiring systemic corticosteroids, change from baseline in trough $\mathrm{FEV}_{1}$, e-diary data (peak expiratory flow, rescue medication use, asthma scores), and asthma control, assessed by overall Asthma Control Questionnaire (ACQ-7) score. ${ }^{20}$ Exploratory end points included impact on productivity and activity, as measured by the Work Productivity and Activity Impairment (WPAI-Asthma) questionnaire, ${ }^{23}$ and Euro Quality of Life-5D Questionnaire (EQ-5D). ${ }^{24}$ All adverse events (AEs) were recorded, including details of severity and relationship to the study drug. Compliance was assessed by counting remaining doses in each study device.

\section{Data Monitoring Committee and interim analysis}

An independent Data Monitoring Committee (DMC) was formed to monitor asthma-related events on behalf of study participants and investigators. The DMC planned to meet every 6 months to review safety data, with an additional event driven review to conduct interim analysis when 10 serious asthma exacerbation events had been accumulated and adjudicated.

One interim analysis was performed and a DMC meeting was held on 31 August 2010 where the DMC reviewed semiblinded safety data. Additional information can be found in the online supplementary appendix section 5 .

\section{Statistical analysis}

Detailed statistical methods are provided in the online supplementary appendix section 6 .

It was estimated that 20 serious asthma exacerbations were required to provide $80 \%$ power to detect a threefold increase in HR at $\alpha=0.05$ (one sided) using nQuery Advisor 7.0 (Statistical Solutions, Cork, Ireland). This was based on assumptions that the annual rate of serious asthma exacerbations would be $0.6 \%$ for $\mathrm{MF}^{25}$ and between $1.8 \%$ and 2.4\% for QMF149, following the FDA meta-analysis, which found asthma-related events in the range of $1.0-1.6 \%$ and estimated a risk difference of 2.80 per 1000 participants for patients receiving LABA treatment compared with non-LABA treatment. ${ }^{13}$ The total of 750 patients per arm was chosen as the average of these two scenarios.

Time to the first serious exacerbation was analysed using a Cox proportional hazards regression model stratified by asthma-related hospitalisation in the last 12 months (no/yes), asthma worsening in the last 12 months (no/yes) and African-American patient (no/ yes), including terms for treatment and region. The annualised rate of exacerbations was evaluated using a negative binomial regression model. Other secondary end points were analysed using a repeated measures analysis of covariance, based on longitudinal measurements, which assumed data were missing at random. No missing data imputation was performed. Analyses were performed using two sided $95 \% \mathrm{CI}$ and $\mathrm{p}$ values.

Efficacy analyses were performed on the full analysis set (all randomised patients receiving at least one dose of randomised study medication, analysed according to randomised study medication). All safety parameters were summarised on the safety set (all patients receiving at least one dose of study medication, analysed according to treatment actually received).

\section{RESULTS \\ Patients}

A total of 1519 patients were randomised to receive treatment (QMF149=756; MF=763) (figure 1). The full analysis set comprised 1508 patients. The median duration of study treatment was 405 and 406 days in the QMF149 and MF treatment groups, respectively. Similar proportions of patients discontinued prematurely in both groups (QMF149=194 (25.7\%) and $\mathrm{MF}=185$ $(24.2 \%))$. The most common reason for early discontinuation of study treatment across both treatment groups was withdrawal of consent $(9.6 \%)$. A higher proportion of patients in the QMF149 group withdrew due to AEs $(5.7 \%)$ compared with the MF treatment group $(3.0 \%)$, but a greater proportion of patients $(2.2 \%)$ in the MF group withdrew due to unsatisfactory therapeutic effect of study treatment compared with the QMF149 treatment group (1.3\%; figure 1).

Baseline demographics and clinical characteristics were well balanced across groups (table 1). The study population presented with a mean baseline (pre-SABA) $\mathrm{FEV}_{1}$ of approximately $75 \%$ predicted and reversibility of approximately 22\%. Similar proportions of patients were compliant with study medication at the final study visit $(91 \%$ and $91.9 \%$ in the QMF149 and MF treatment groups, respectively).

\section{Serious asthma exacerbations}

In total, eight patients (two QMF149 and six MF) experienced a serious asthma exacerbation; none required intubation or resulted in death. There were too few events to estimate the time to first serious asthma exacerbation at most percentiles. The difference between QMF149 and MF did not reach statistical significance $(\mathrm{HR}=0.31 ; 95 \%$ CI 0.06 to $1.54, \mathrm{p}=0.151$ (table 2$))$. The difference in the cumulative incidence of serious asthma exacerbation between the QMF149 and MF treatment groups was -0.52 percentage point $(95 \%$ CI -1.25 to $0.21, \mathrm{p}=0.160$ ).

\section{Asthma exacerbations requiring systemic corticosteroids}

More patients in the MF group had an asthma exacerbation requiring treatment with systemic corticosteroids compared with the QMF149 group (22.5\% and 16.6\%, respectively; difference 5.9 percentage points). 
Figure 1 Patient flow through the study (CONSORT diagram).

*Patients could be allocated to more than one group concerning reason for exclusion.

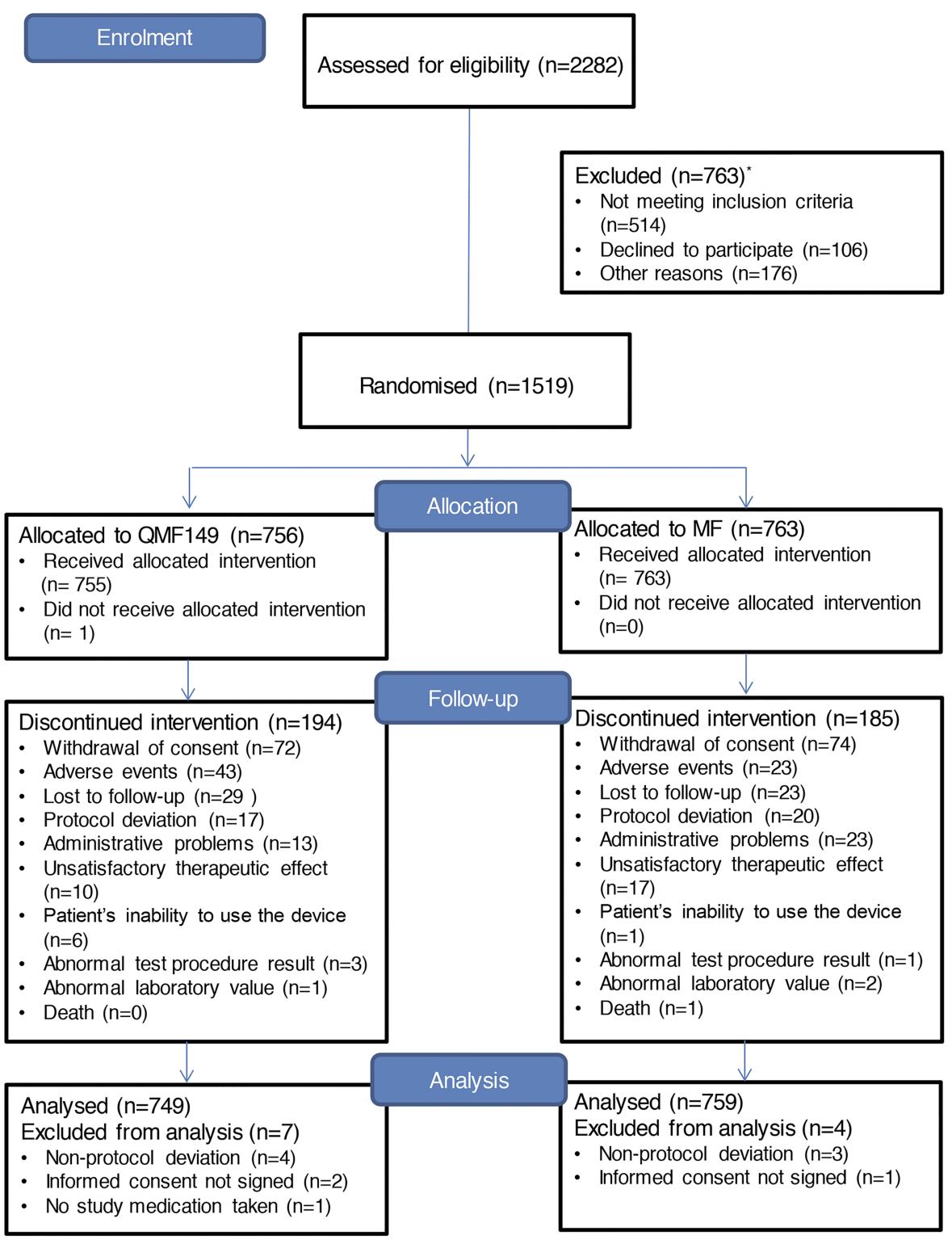

QMF149 significantly reduced the risk in the time to first exacerbation requiring systemic corticosteroids by $30 \% \quad(\mathrm{HR}=0.70 ; 95 \%$ CI 0.56 to $0.89, \mathrm{p}=0.003$; figure 2 ) and the annual rate of exacerbations requiring systemic corticosteroids by $29 \%$ (rate ratio $=0.71 ; 95 \%$ CI 0.55 to $0.90, \mathrm{p}=0.005$ ) compared with MF.

\section{Lung function}

Trough $\mathrm{FEV}_{1}$ significantly improved during treatment with QMF149 compared with MF at all study visits (table 3). Improvements at week 4 were maintained over 68 weeks with treatment differences ranging from $0.10 \mathrm{~L}$ (95\% CI 0.05 to 0.15$)$ to $0.14 \mathrm{~L}(0.11$ to $0.18 ; \mathrm{p} \leq 0.001$ at all visits). Compared with MF, QMF149 also resulted in significantly $(p \leq 0.001)$ greater improvements in forced vital capacity (FVC) at each visit (day 1, weeks 4-68).

The adjusted mean treatment difference (QMF149MF) for changes from baseline in morning and evening peak expiratory flow were statistically significant in favour of QMF149 (adjusted mean difference $0.44 \mathrm{~L} / \mathrm{s}$ (95\% CI 0.36 to 0.52$)$ and $0.42 \mathrm{~L} / \mathrm{s}(0.34$ to 0.50$)$, respectively, both $\mathrm{p} \leq 0.001$ ).

\section{Asthma symptoms, rescue medication use and asthma control}

The percentage of days with no asthma symptoms was significantly increased during treatment with QMF149 compared with MF (table 3). Adjusted mean treatment differences during the morning, daytime and night-time were $3.9 \%$ (95\% CI 1.5 to 6.3 ), $7.7 \%$ (95\% CI 4.5 to 10.9 ) and $6.3 \%$ of days (95\% CI 3.4 to 9.2$)$, respectively. QMF149 also significantly increased the percentage of days with no rescue medication use during daytime, night-time and 24-h periods compared with MF. Adjusted mean treatment differences ranged from 9.8\% 
Table 1 Baseline demographic and clinical characteristics

\begin{tabular}{|c|c|c|c|}
\hline & $\begin{array}{l}\text { QMF149 } \\
(n=749)\end{array}$ & $\begin{array}{l}\text { MF } \\
(n=759)\end{array}$ & $\begin{array}{l}\text { Total } \\
(\mathrm{N}=1508)\end{array}$ \\
\hline Age (years) & $42.4(14.75)$ & 42.3 (14.58) & $42.3(14.66)$ \\
\hline \multicolumn{4}{|l|}{ Age group (years) } \\
\hline$<18$ & 31 (4.1\%) & 35 (4.6\%) & 66 (4.4\%) \\
\hline $18-64$ & $675(90.1 \%)$ & $682(89.9 \%)$ & $1357(90.0 \%)$ \\
\hline$\geq 65$ & $43(5.7 \%)$ & $42(5.5 \%)$ & $85(5.6 \%)$ \\
\hline \multicolumn{4}{|l|}{ Sex } \\
\hline Male & 313 (41.8\%) & 310 (40.8\%) & $623(41.3 \%)$ \\
\hline Female & 436 (58.2\%) & 449 (59.2\%) & 885 (58.7\%) \\
\hline \multicolumn{4}{|l|}{ Race } \\
\hline Caucasian & 460 (61.4\%) & $474(62.5 \%)$ & $934(61.9 \%)$ \\
\hline Asian & 142 (19.0\%) & $143(18.8 \%)$ & 285 (18.9\%) \\
\hline Black & $58(7.7 \%)$ & $53(7.0 \%)$ & $111(7.4 \%)$ \\
\hline Other & $89(11.9 \%)$ & $89(11.7 \%)$ & $178(11.8 \%)$ \\
\hline BMI $\left(\mathrm{kg} / \mathrm{m}^{2}\right)$ & $27.4(6.33)$ & $27.5(6.37)$ & $27.5(6.35)$ \\
\hline \multicolumn{4}{|l|}{ Smoking history } \\
\hline Never smoked & $631(84.2)$ & 635 (83.7) & 1266 (84.0) \\
\hline Ex-smoker & 117 (15.6) & 123 (16.2) & $240(15.9)$ \\
\hline $\mathrm{FEV}_{1}$ before inhalation of SABA (L) & $2.29(0.773)$ & $2.30(0.755)$ & $2.29(0.764)$ \\
\hline FEV 1 before inhalation of SABA ( $\%$ of predicted $\mathrm{FEV}_{1}$ ) & $75.1(15.86)$ & $75.5(15.28)$ & $75.3(15.56)$ \\
\hline FEV 1 reversibility $(\%)$ & $21.6(13.46)$ & $21.8(13.61)$ & $21.7(13.53)$ \\
\hline Mean ACQ-7 score at baseline & 1.7 & 1.7 & 1.7 \\
\hline
\end{tabular}

(95\% CI 6.8 to 12.8 ) to $11.3 \%$ of days (8.1 to 14.4 ; all $\mathrm{p}<0.001)$.

Asthma control, as assessed by ACQ-7 score, was significantly improved with QMF149 compared with MF by week 4 and thereafter at each subsequent visit throughout the treatment period (table 3). Adjusted mean treatment differences between QMF149 and MF ranged from -0.13 (-0.20 to -0.06$)$ to $-0.23(-0.33$ to -0.13 ; all $\mathrm{p}<0.001)$, with an overall adjusted mean difference of -0.19 ( -0.25 to -0.14 ; $\mathrm{p}<0.001)$ in favour of QMF149. The overall changes from baseline were -0.49 for QMF149 and -0.29 for MF.

Improvements from baseline in EQ-5D were similar in the QMF149 and MF treatment groups. For WPAI-asthma, change from baseline in the percentage of activity

Table 2 Time to first serious exacerbation - summary statistical and Cox regression analysis

\begin{tabular}{|c|c|c|}
\hline & $\begin{array}{l}\text { QMF149 } \\
(n=749)\end{array}$ & $\begin{array}{l}\text { MF } \\
(n=759)\end{array}$ \\
\hline Patients with serious asthma exacerbation & $2(0.3 \%)$ & $6(0.8 \%)$ \\
\hline Difference in cumulative incidences $\%(95 \% \mathrm{Cl})$ & $-0.52(-1.25$ to 0.21$)$ & $p=0.160$ \\
\hline Follow-up time, median months (range) & $13.3(0-19.6)$ & $13.4(0-20.3)$ \\
\hline \multicolumn{3}{|l|}{ Event-free rates \% $(95 \% \mathrm{Cl})$} \\
\hline 6 months & 99.7 (98.8 to 99.9) & 99.7 (98.9 to 99.9$)$ \\
\hline 12 months & 99.7 (98.8 to 99.9$)$ & 99.3 (98.2 to 99.7$)$ \\
\hline 18 months & 99.7 (98.8 to 99.9$)$ & 99.0 (97.6 to 99.5$)$ \\
\hline 21 months & - & - \\
\hline \multicolumn{3}{|l|}{ Cox regression analysis } \\
\hline \multirow[t]{2}{*}{ HR QMF149/MF (95\% Cl) } & $0.31(0.06$ to 1.54$)$ & \\
\hline & & $p=0.151$ \\
\hline \multicolumn{3}{|c|}{$\begin{array}{l}\text { Data are } n(\%) \text { unless otherwise specified. Patients who did not experience a serious asthma exacerbation were censored at their last } \\
\text { follow-up date. Follow-up time=time from randomisation until the first serious asthma exacerbation or censoring. Event-free time rates were } \\
\text { calculated by the Kaplan Meier method. The Cox regression model included the terms for treatment and region, stratified by history of asthma } \\
\text { related hospitalisation in the past } 12 \text { months (yes/no), history of asthma worsening in the past } 12 \text { months (yes/no) and African-American } \\
\text { patient (yes/no). A HR }<1 \text { favours QMF149. } \\
\text { Cl, confidence interval; MF, mometasone furoate; MR, mometasone. }\end{array}$} \\
\hline
\end{tabular}


Figure 2 Kaplan-Meier plot of time to first asthma exacerbation requiring treatment with systemic corticosteroids.

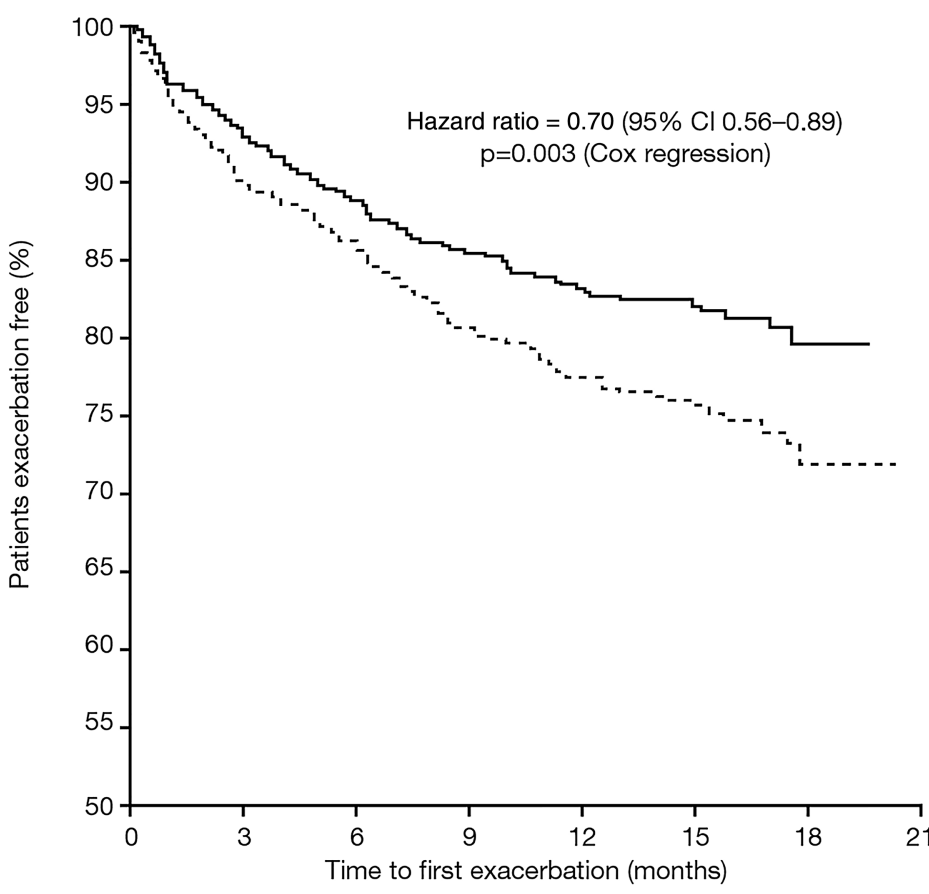

Treatment QMF149 _........ MF

Numbers at risk

$\begin{array}{llllllll}\text { QMF149 } & 749 & 648 & 595 & 549 & 415 & 218 & 66 \\ \text { MF } & 759 & 644 & 591 & 533 & 411 & 119 & 57\end{array}$

impairment during work caused by asthma was statistically significantly reduced (improved) in the QMF149 treatment group compared with the MF treatment group overall $(-1.5(-2.7$ to -0.2$) ; \mathrm{p}=0.022)$, at week $12(-1.8$ $(-3.5$ to -0.2$) ; \mathrm{p}=0.032)$ and at the final clinic visit $(-2.2$ $(-4.2$ to -0.3$) ; \mathrm{p}=0.026)$.

Table 3 Changes from baseline in trough $\mathrm{FEV}_{1}$ and ACQ-7 average score by visit, and asthma symptoms summarised throughout the treatment period

\begin{tabular}{|c|c|c|c|c|c|c|c|c|c|}
\hline \multirow[b]{2}{*}{ Variable } & \multicolumn{3}{|l|}{ QMF149 } & \multicolumn{3}{|l|}{ MF } & \multicolumn{3}{|c|}{ Treatment difference: QMF149-MF } \\
\hline & $\mathrm{n}(\%)$ & LS mean & SE & $\mathrm{n}(\%)$ & LS mean & SE & LS mean & SE & $95 \% \mathrm{Cl}$ \\
\hline \multicolumn{10}{|c|}{ Change from baseline in trough $\mathrm{FEV}_{1}$ by visit $(\mathrm{L})$} \\
\hline Overall & $727(100)$ & 0.07 & 0.023 & $746(100)$ & -0.05 & 0.023 & $0.12^{\star \star \star}$ & 0.014 & (0.09 to 0.15$)$ \\
\hline Week 4 & 709 (97.5) & 0.09 & 0.023 & $728(97.6)$ & -0.04 & 0.023 & $0.13^{\star \star \star}$ & 0.014 & (0.10 to 0.16$)$ \\
\hline Week 12 & $681(93.7)$ & 0.08 & 0.024 & 693 (92.9) & -0.02 & 0.024 & $0.11^{\star \star \star *}$ & 0.016 & (0.08 to 0.14$)$ \\
\hline Week 26 & $643(88.4)$ & 0.08 & 0.024 & 658 (88.2) & -0.04 & 0.024 & $0.12^{\star \star \star}$ & 0.017 & (0.08 to 0.15$)$ \\
\hline Week 52 & 431 (59.3) & 0.07 & 0.025 & $443(59.4)$ & -0.07 & 0.025 & $0.14^{\star \star \star}$ & 0.018 & (0.11 to 0.18 ) \\
\hline Week 68 & 176 (24.2) & 0.06 & 0.028 & 171 (22.9) & -0.05 & 0.028 & $0.10^{\star \star \star}$ & 0.026 & (0.05 to 0.15$)$ \\
\hline Final visit & $674(92.7)$ & 0.06 & 0.025 & 699 (93.7) & -0.07 & 0.024 & $0.12^{\star \star \star}$ & 0.018 & (0.09 to 0.16$)$ \\
\hline \multicolumn{10}{|c|}{ Change from baseline in ACQ-7 score by visit } \\
\hline Overall & $728(100)$ & -0.49 & 0.049 & $745(100)$ & -0.29 & 0.049 & $-0.19^{\star \star \star}$ & 0.028 & $(-0.25$ to -0.14$)$ \\
\hline Week 4 & 709 (97.4) & -0.35 & 0.049 & $734(98.5)$ & -0.15 & 0.049 & $-0.20^{\star \star \star}$ & 0.031 & $(-0.26$ to -0.14$)$ \\
\hline Week 12 & 679 (93.3) & -0.45 & 0.050 & 697 (93.6) & -0.24 & 0.050 & $-0.21^{\star \star *}$ & 0.034 & $(-0.28$ to -0.15$)$ \\
\hline Week 26 & $648(89.0)$ & -0.50 & 0.051 & $660(88.6)$ & -0.38 & 0.051 & $-0.13^{\star \star \star}$ & 0.035 & $(-0.20$ to -0.06$)$ \\
\hline Week 52 & 432 (59.3) & -0.52 & 0.052 & 447 (60.0) & -0.35 & 0.052 & $-0.17^{\star \star \star}$ & 0.038 & $(-0.24$ to -0.10$)$ \\
\hline Week 68 & $178(24.5)$ & -0.55 & 0.056 & 173 (23.2) & -0.32 & 0.057 & $-0.23^{\star \star \star}$ & 0.050 & $(-0.33$ to -0.13$)$ \\
\hline Final visit & 675 (92.7) & -0.55 & 0.052 & 687 (92.2) & -0.32 & 0.052 & $-0.22^{\star \star \star}$ & 0.040 & $(-0.30$ to -0.14$)$ \\
\hline \multicolumn{10}{|c|}{ Percentage of days with no asthma symptoms during } \\
\hline Morning & 730 & 22.3 & 2.17 & 746 & 18.4 & 2.17 & $3.9^{\star \star \star}$ & 1.20 & $(1.5$ to 6.3$)$ \\
\hline Daytime & 731 & 27.1 & 2.96 & 749 & 19.5 & 2.95 & $7.7^{* * *}$ & 1.63 & (4.5 to 10.9$)$ \\
\hline Night-time & 730 & 23.6 & 2.69 & 746 & 17.3 & 2.68 & $6.3^{* * *}$ & 1.49 & (3.4 to 9.2 ) \\
\hline
\end{tabular}




\section{Safety}

The median number of days of exposure was 405 days in the QMF149 group and 406 days in the MF group. Serious AE (SAEs) occurred in $4.0 \%$ of patients in the QMF149 group and 5.8\% of patients in the MF group. Asthma (defined as asthma worsening and/or asthma exacerbation) was the most frequent SAE, reported by two patients in the QMF group $(0.3 \%)$ and nine patients in the MF group (1.2\%) (see online supplementary table S1 and appendix section 7). The other most frequently reported SAEs were pneumonia (none with QMF149 and $4(0.5 \%)$ with MF; confirmed by either radiographic evidence or investigator examination) and appendicitis (2 $(0.3 \%)$ in each group). Seven patients $(0.9 \%)$ in both treatment groups discontinued treatment because of an SAE. There was one death (in the MF group) due to multiorgan failure following surgery that was not treatment or asthma related.

The overall incidence of AEs was similar in both treatment groups: 554 QMF149 patients (74\%) and $557 \mathrm{MF}$ patients $(73.4 \%)$ (see online supplementary table S2 and appendix section 7). Treatment-related AEs (TRAEs) (as per investigator assessment) were reported in $269(35.9 \%)$ and $81(10.7 \%)$ patients in the QMF149 and MF groups, respectively. The most frequently occurring AEs (in $>1 \%$ patients in either group) were asthma and cough (see online supplementary table S3).

Overall, asthma was reported as an AE in 275 (36\%) patients in the MF group and 196 (26\%) patients in the QMF149 group, and as a TRAE in $21(3 \%)$ and $13(2 \%)$ patients in the two groups, respectively. Cough was reported overall as an $\mathrm{AE}$ in $266(36 \%)$ patients in the QMF149 group and in $64(8 \%)$ patients in the MF group, and as a TRAE in $238(32 \%)$ and $32(4 \%)$ patients in the two groups, respectively.

\section{DISCUSSION}

This phase II study has shown a favourable safety/efficacy profile for once-daily QMF149 in the treatment of adolescents and adults with persistent asthma. Compared with MF, treatment with QMF149 demonstrated a trend towards reducing the risk of serious asthma exacerbations, and a significant reduction of $29 \%$ in the annual rate of asthma exacerbations requiring systemic corticosteroids. QMF149 also resulted in significant improvements in lung function, asthma symptoms and asthma control.

In this study, the HR for the risk of serious exacerbations was numerically in favour of QMF149 but was not significant $(0.31 ; 95 \%$ CI 0.06 to $1.54, \mathrm{p}=0.151)$. Based on the Wolfe et $a l^{25}$ study and event rates in the FDA LABA safety meta-analysis, ${ }^{13}$ it was predicted that the sample size of 1500 patients would result in 20 serious asthma exacerbations during this study, thereby providing $80 \%$ power to detect a threefold increase in HR with QMF149. The numbers of serious asthma exacerbations were lower than predicted in the QMF149 treatment group with a corresponding reduction in power and wider CI. However, the low event rate may be seen as indirect evidence that both treatments are effective in the prevention of serious asthma events.

These findings are consistent with those from previous studies of currently prescribed LABA/ICS products. ${ }^{10} 11$ To date, there has been no evidence that fixed-dose combinations of salmeterol/fluticasone propionate ${ }^{11}$ or formoterol/budesonide, ${ }^{10}$ both of which require twicedaily administration, are associated with an increased risk of serious asthma exacerbations leading to hospital admission, intubation or death, compared with ICS therapy. However, the interpretation relating to mortality is limited to some extent by the low statistical power of the available studies for this outcome.

The primary outcome variable was time to first serious asthma exacerbation resulting in hospital admission, intubation or mortality, based on that mandated by the FDA in a series of related randomised controlled trials of LABA/ICS products currently used in the treatment of asthma. ${ }^{14}$ The use of this outcome variable recognises that it is difficult to assess mortality alone as a primary outcome variable in clinical trials of asthma, largely owing to its rarity, even in patients with moderateto-severe disease. This is well illustrated by an independent analysis of a salmeterol database, in which there were no deaths or intubations among more than 22000 subjects in the 63 studies of salmeterol/fluticasone propionate. ${ }^{11}$ The outcome's rationale is also based on the observation that an increased risk in hospital admission tracks with mortality risk in studies of LABA therapy and, as a result, hospital admissions can be considered an acceptable surrogate for risk of mortality. ${ }^{11}$

A further clinically important outcome was the time to first asthma exacerbation requiring treatment with systemic corticosteroids. There was a clear difference between treatment groups for this end point with $17 \%$ of QMF149 patients experiencing exacerbations requiring systemic corticosteroids compared with $23 \%$ receiving MF. Overall, there was a $30 \%$ reduction in risk in the time to first exacerbation requiring treatment with systemic corticosteroids in patients receiving QMF149 compared with MF. Similarly, asthma reported as an AE (defined as asthma worsening and/or asthma exacerbation) occurred more frequently in the MF treatment group $(36 \%)$ compared with the QMF149 treatment group (26\%).

Lung function, assessed as change from baseline in trough $\mathrm{FEV}_{1}$, showed statistically significant treatment differences in favour of QMF149, ranging between $0.10 \mathrm{~L}$ and $0.14 \mathrm{~L}$ throughout the study period. These differences between two active treatments are within the range considered to be clinically relevant for treatments compared with placebo. ${ }^{26} 27$ This demonstrated persistence of efficacy during the treatment period, with no evidence of bronchodilator tolerance.

Other secondary efficacy variables such as symptomfree days (morning, daytime and night-time) and rescue 
medication use showed statistically significant treatment differences in favour of QMF149 throughout the study. Such improvements over MF are consistent with those demonstrated with other LABA/ICS combination therapies compared with ICS used as monotherapy. ${ }^{89}$

Improvements in asthma control as measured with the ACQ-7 were consistently statistically significantly higher with QMF149 compared with MF. QMF149 achieved an overall improvement of -0.49 from baseline, which is considered clinically relevant. ${ }^{28}$ Clinically relevant improvements were not demonstrated in the MF treatment group.

QMF149 is comprised of two molecules with established efficacy and safety profiles. The indacaterol maleate dose, selected from dose ranging studies in asthma, results in rapid onset bronchodilation that is maintained for at least $24 \mathrm{~h}^{15}{ }^{21}$ Once-daily dosing is established as an effective regimen for $\mathrm{MF}^{22}{ }^{29}$ The use of a once-daily evening dose of $400 \mu \mathrm{g}$ was based on a clinical trial programme, which demonstrated that $400 \mu \mathrm{g}$ is near the top of the therapeutic dose-response curve in persistent asthma, ${ }^{22}$ that once-daily was as efficacious as twice-daily dosing ${ }^{29}$ and that evening may be superior to morning dosing. ${ }^{30}$ The choice of MF as the ICS component was also based on its favourable efficacy/safety profile. $^{31}$ Thus, indacaterol maleate and MF have established efficacy when used once daily in the evening. It is possible that once-daily dosing of LABA/ICS products may lead to improved compliance ${ }^{19}$ and, thereby, efficacy compared with twice-daily regimens; however, this issue requires further study.

While the assessment of safety was based primarily on serious asthma exacerbations and exacerbations requiring systemic corticosteroids, the trial was of sufficient duration to assess the overall safety profile of QMF149, and AEs were recorded rigorously throughout the study. In general, the incidence of AEs was similar across the treatment groups with the exception of asthma and cough. The higher incidence of cough in the QMF149 treatment group was likely due to the use of the maleate salt of indacaterol in this study. A study comparing the maleate with the acetate salt of indacaterol showed that indacaterol acetate is associated with a lower incidence of cough with no impact on the efficacy, safety, or tolerability of treatment (Novartis data on file, 2012). Future studies of QMF149 will use indacaterol acetate rather than indacaterol maleate.

In addition, based on systemic exposure comparisons for indacaterol ${ }^{32}{ }^{33}$ and MF, ${ }^{34}$ QMF149 will be delivered via the Breezhaler device in future development, rather than the Twisthaler device marketed for MF. QMF149 delivered via the Breezhaler device is currently being evaluated as a fixed-dose combination, where a dose of indacaterol acetate $150 \mu \mathrm{g} / \mathrm{MF} 160 \mu \mathrm{g}$ is comparable to indacaterol maleate $500 \mu \mathrm{g} / \mathrm{MF} 400 \mu \mathrm{g}$ delivered via the Twisthaler device. Thus, since QMF149 $150 \mu \mathrm{g} / 160 \mu \mathrm{g}$ via the Breezhaler device with the acetate salt is expected to be clinically comparable to QMF149 $500 \mu \mathrm{g} / 400 \mu \mathrm{g}$ with the maleate salt via the Twisthaler device, the current study provides important data to support the safety and efficacy profile of the final product.

In conclusion, this study has shown a favourable safety/efficacy profile of QMF149 in the treatment of persistent asthma. Improvements in lung function, symptom control and rescue medication use, and reductions in risk in time to first exacerbation requiring systemic corticosteroids, and in the annual rate of asthma exacerbations requiring systemic corticosteroids, were all significantly in favour of treatment with QMF149. QMF149 treatment was also associated with a numerical, but not significant, reduction in the risk of serious asthma exacerbations. QMF149 may be a useful treatment option in adolescents and adults with asthma who qualify for treatment with a LABA/ICS combination.

\section{Author affiliations}

${ }^{1}$ Medical Research Institute of New Zealand, Wellington, New Zealand ${ }^{2}$ Department of Medicine, University of North Carolina, Chapel Hill, North Carolina, USA

${ }^{3}$ Dr Mehta's Allergy \& Asthma Care and Research Center, Indore, Madhya Pradesh, India

${ }^{4}$ National Jewish Health, Denver, Colorado, USA

${ }^{5}$ Novartis Horsham Research Centre, Horsham, West Sussex, UK

${ }^{6}$ Novartis Pharmaceuticals Corporation, East Hanover, New Jersey, USA

${ }^{7}$ Novartis Pharmaceuticals Corporation, Basel, Switzerland

Acknowledgements The authors wish to thank Jennifer Li (Novartis Pharmaceuticals Corporation) who provided additional statistical analysis and contributed to data interpretation, Motoi Hosoe (Novartis Pharma AG) who contributed to data interpretation and Mary Sayers, a professional medical writer contracted to CircleScience, an Ashfield Company, part of UDG Healthcare plc who assisted the authors in the preparation of the manuscript.

Contributors RM was a principal investigator directly involved in the recruitment and care of the participants, and in data collection. MC, BMH and AM (current and ex-employees of the funding source) contributed to study design and conduct, data analysis and interpretation. H-JK (ex-employee of the funding source) contributed to study design, performed the statistical analysis and contributed to data interpretation. RWB was involved in the interpretation of statistical analyses. JFD and HSN both served on the Adjudication Committee for the current study. RWB took primary responsibility for writing the manuscript. All authors had access to the study data, were involved in interpretation and/or presentation of the data for this report, reviewed and revised the initial draft and subsequent versions of the manuscript, had final responsibility for the decision to submit for publication and approved the version submitted.

Funding The study was sponsored by Novartis Pharma AG.

Competing interests RWB received funding support from Novartis to present the study findings at the European Respiratory Society 2012 Annual Scientific Meeting. He has been a member of the GlaxoSmithKline (NZ) Advisory Board; consulted for Cytos Biotechnology and Pharmaxis; received research grants from AstraZeneca, Cephalon, Chiesi, Genentech, GlaxoSmithKline and Novartis; and received payment for lectures or support to attend meetings from Boehringer Ingelheim, GlaxoSmithKline, Novartis, Nycomed and Otsuka Pharmaceuticals. JFD served on the Adjudication Committee for the current study and has served on data monitoring safety boards for other Novartis clinical studies as well as for PneumoRx, Otsuka and Teva. He has received payment from Novartis for consultancy and expert testimony, and also served as a consultant for Almirall, AstraZeneca, Boehringer Ingelheim,

GlaxoSmithKline, Forest, Merck, Pfizer, Sunovian, Pearl, Mylan and Gilead. RM was a principal investigator for the current study. HSN has consulted for Merck, Pearl Therapeutics and Circassia and has received research grants from NIH, Circassia and the Immune Tolerance Network. He served on the Adjudication Committee for the current study. BMH is an employee of 
Novartis Pharmaceuticals Corporation. MC, AM and H-JK are ex-employees of Novartis Pharmaceuticals Corporation.

Ethics approval Ethics committees for each investigator site.

Provenance and peer review Not commissioned; externally peer reviewed.

Data sharing statement No additional data are available.

Open Access This is an Open Access article distributed in accordance with the Creative Commons Attribution Non Commercial (CC BY-NC 4.0) license, which permits others to distribute, remix, adapt, build upon this work noncommercially, and license their derivative works on different terms, provided the original work is properly cited and the use is non-commercial. See: http:// creativecommons.org/licenses/by-nc/4.0/

\section{REFERENCES}

1. Global Initiative for Asthma (GINA). Global Strategy for Asthma Management and Prevention. 2012. http://www.ginasthma.org/ local/uploads/files/GINA_Report_March13.pdf (accessed Jun 2014)

2. NHLBI. Expert Panel Report 3: Guidelines for the diagnosis and management of asthma. Full report. National Institutes of Health, National Heart Lung and Blood Institute, 2007. http://www.nhlbi.nih. gov/health-pro/guidelines/current/asthma-guidelines/full-report (accessed 28 Jan 2015).

3. Beasley R, Fingleton J, Weatherall M. Restriction of LABA use to combination ICS/LABA inhaler therapy in asthma. Thorax 2013;68:119-20.

4. Rodrigo GJ, Castro-Rodriguez JA. Safety of long-acting beta agonists for the treatment of asthma: clearing the air. Thorax 2012;67:342-9.

5. Stempel DA, Stoloff SW, Carranza R Jr, et al. Adherence to asthma controller medication regimens. Respir Med 2005;99:1263-7.

6. Stoloff SW, Stempel DA, Meyer J, et al. Improved refill persistence with fluticasone propionate and salmeterol in a single inhaler compared with other controller therapies. J Allergy Clin Immunol 2004:113:245-51.

7. Suissa $\mathrm{S}$, Ernst $\mathrm{P}$, Benayoun $\mathrm{S}$, et al. Low-dose inhaled corticosteroids and the prevention of death from asthma. $N$ Engl $J$ Med 2000;343:332-6.

8. Bateman ED, Boushey HA, Bousquet $\mathrm{J}$, et al. Can guideline-defined asthma control be achieved? The Gaining Optimal Asthma ControL study. Am J Respir Crit Care Med 2004;170:836-44.

9. Zetterström $\mathrm{O}$, Buhl $\mathrm{R}$, Mellem $\mathrm{H}$, et al. Improved asthma control with budesonide/formoterol in a single inhaler, compared with budesonide alone. Eur Respir J 2001;18:262-8.

10. Sears MR, Radner F. Safety of budesonide/formoterol maintenance and reliever therapy in asthma trials. Respir Med 2009:103:1960-8.

11. Weatherall $\mathrm{M}$, Wijesinghe $\mathrm{M}$, Perrin $\mathrm{K}$, et al. Meta-analysis of the risk of mortality with salmeterol and the effect of concomitant inhaled corticosteroid therapy. Thorax 2010;65:39-43.

12. Nelson HS, Weiss ST, Bleecker ER, et al. The Salmeterol Multicenter Asthma Research Trial: a comparison of usual pharmacotherapy for asthma or usual pharmacotherapy plus salmeterol. Chest 2006;129:15-26.

13. Levenson M. Long-acting beta-agonists and adverse asthma events meta-analysis. US Food and Drug Administration Center for Drug Evaluation and Research (CDER). Joint meeting of the pulmonaryallergy drugs advisory committee, drug safety and risk management advisory committee and the pediatric advisory committee. 10 December 2008. http://www.fda.gov/ohrms/dockets/ac/08/briefing/ 2008-4398b1-01-FDA.pdf (accessed 28 Jan 2015).
14. Chowdhury BA, Seymour SM, Levenson MS. Assessing the safety of adding LABAs to inhaled corticosteroids for treating asthma. N Engl J Med 2011;364:2473-5.

15. Chuchalin AG, Tsoi AN, Richter K, et al. Safety and tolerability of indacaterol in asthma: a randomized, placebo-controlled 28-day study. Respir Med 2007;101:2065-75.

16. Karpel JP, Nelson H. Mometasone furoate dry powder inhaler: a once-daily inhaled corticosteroid for the treatment of persistent asthma. Curr Med Res Opin 2007;23:2897-911.

17. Laforce $\mathrm{C}$, Korenblat $\mathrm{P}$, Osborne $\mathrm{P}$, et al. 24-hour bronchodilator efficacy of single doses of indacaterol in patients with persistent asthma: comparison with placebo and formoterol. Curr Med Res Opin 2009;25:2353-9.

18. McCormack PL, Plosker GL. Inhaled mometasone furoate: a review of its use in persistent asthma in adults and adolescents. Drugs 2006;66:1151-68.

19. Claxton AJ, Cramer J, Pierce C. A systematic review of the associations between dose regimens and medication compliance. Clin Ther 2001;23:1296-310.

20. Juniper EF, O'Byrne PM, Guyatt GH, et al. Development and validation of a questionnaire to measure asthma control. Eur Respir J 1999;14:902-7.

21. Laforce $\mathrm{C}$, Alexander $\mathrm{M}$, Deckelmann $\mathrm{R}$, et al. Indacaterol provides sustained $24 \mathrm{~h}$ bronchodilation on once-daily dosing in asthma: a 7-day dose-ranging study. Allergy 2008;63:103-11.

22. Hart K, Weatherall M, Shirtcliffe $P$, et al. Frequency of dosing and comparative doses of mometasone furoate: a meta-analysis. Respirology 2009;14:1166-72.

23. Andréasson $\mathrm{E}$, Svensson $\mathrm{K}$, Berggren $\mathrm{F}$. The validity of the work productivity and activity impairment questionnaire for patients with asthma (WPAl-asthma): results from a web-based study. Value Health 2003;6:780.

24. Brooks RG. EuroQoL: the current state of play. Health Policy 1996:37:53-72.

25. Wolfe J, Laforce C, Friedman B, et al. Formoterol, 24 microg bid, and serious asthma exacerbations: similar rates compared with formoterol, 12 microg bid, with and without extra doses taken on demand, and placebo. Chest 2006;129:27-38.

26. Santanello NC, Zhang J, Seidenberg B, et al. What are minimal important changes for asthma measures in a clinical trial? Eur Respir J 1999; 14:23-7.

27. Tepper RS, Wise RS, Covar R, et al. Asthma outcomes: pulmonary physiology. J Allergy Clin Immunol 2012;129: S65-87.

28. Juniper EF, Svensson K, Mork AC, et al. Measurement properties and interpretation of three shortened versions of the asthma control questionnaire. Respir Med 2005;99:553-8.

29. Kemp JP, Berkowitz RB, Miller SD, et al. Mometasone furoate administered once daily is as effective as twice-daily administration for treatment of mild-to-moderate persistent asthma. J Allergy Clin Immunol 2000;106:485-92.

30. Noonan M, Karpel JP, Bensch GW, et al. Comparison of once-daily to twice-daily treatment with mometasone furoate dry powder inhaler. Ann Allergy Asthma Immunol 2001;86:36-43.

31. Bousquet J, D'Urzo A, Hebert $\mathrm{J}$, et al. Comparison of the efficacy and safety of mometasone furoate dry powder inhaler to budesonide Turbuhaler. Eur Respir J 2000;16:808-16.

32. Lock R, Price D, Khindri S, et al. Efficient deposition and absorption of orally inhaled indacaterol in the lungs. Eur Respir J 2011;38 (Suppl 55):P252.

33. Vaidya $\mathrm{S}$, Khindri $\mathrm{S}$, Maahs $\mathrm{S}$, et al. Evaluation of lung delivery of indacaterol following inhalation via QMF149 Twisthaler $^{\circledR}(\mathrm{TH})$ in healthy volunteers. Clin Pharm Drug Develop 2012;1:P197.

34. Vaidya S, Khindri S, Robinson J, et al. Pharmacokinetics (PK) of single doses of mometasone furoate (MF) delivered via the Breezhaler $^{\circledR}(\mathrm{BH})$ and Twisthaler ${ }^{\circledR}(\mathrm{TH})$ devices in healthy subjects. Eur Respir J 2012;40(Suppl 56):P382. 